\title{
The influence of systemic hemodynamics and oxygen transport on cerebral oxygen saturation in neonates after the Norwood procedure
}

\author{
Jia Li, MD, PhD, ${ }^{a}$ Gencheng Zhang, MD, PhD, ${ }^{a}$ Helen Holtby, MD, ${ }^{a}$ Anne-Marie Guerguerian, MD, ${ }^{\text {a }}$ Sally Cai, ${ }^{\text {b }}$
}

Tilman Humpl, MD, ${ }^{a}$ Christopher A. Caldarone, MD, ${ }^{a}$ Andrew N. Redington, MD, a and Glen S. Van Arsdell, MDa

Supplemental material is available online.
From the Heart Center, the Hospital for Sick Children, ${ }^{\text {a }}$ Toronto, Ontario, Canada; and the Data Center, Congenital Heart Surgeon's Society, ${ }^{\mathrm{b}}$ Toronto, Ontario, Canada.

This work was supported by the Heart and Stroke Foundation of Canada and the Canadian Institute of Health Research (J.L., A.M.G., A.N.R., and G.S.V.).

Received for publication April 27, 2007; revisions received June 8, 2007; accepted for publication July 9, 2007.

Address for reprints: Jia $\mathrm{Li}, \mathrm{MD}, \mathrm{PhD}$, Division of Cardiology, Hospital for Sick Children, 555 University Ave, Toronto, Ontario, Canada M5G 1X8 (E-mail: jia.li@ sickkids.ca).

J Thorac Cardiovasc Surg 2008;135:83-90

0022-5223/ $\$ 34.00$

Copyright $\odot 2008$ by The American Association for Thoracic Surgery

doi:10.1016/j.jtcvs.2007.07.036
Objectives: Ischemic brain injury is an important morbidity in neonates after the Norwood procedure. Its relationship to systemic hemodynamic oxygen transport is poorly understood.

Methods: Sixteen neonates undergoing the Norwood procedure were studied. Continuous cerebral oxygen saturation was measured by near-infrared spectroscopy. Continuous oxygen consumption was measured by respiratory mass spectrometry. Pulmonary and systemic blood flow, systemic vascular resistance, oxygen delivery, and oxygen extraction ratio were derived with measurements of arterial, and superior vena cava and pulmonary venous gases and pressures at 2- to 4-hour intervals during the first 72 hours in the intensive care unit.

Results: Mean cerebral oxygen saturation was $66 \% \pm 12 \%$ before the operation, reduced to $51 \% \pm 13 \%$ on arrival in the intensive care unit, and remained low during the first 8 hours; it increased to $56 \% \pm 9 \%$ at 72 hours, still significantly lower than the preoperative level $(P<.05)$. Postoperatively, cerebral oxygen saturation was closely and positively correlated with systemic arterial pressure, arterial oxygen saturation, and arterial oxygen tension and negatively with oxygen extraction ratio $(P<.0001$ for all). Cerebral oxygen saturation was moderately and positively correlated with systemic blood flow and oxygen delivery $(P<.0001$ for both). It was weakly and positively correlated with pulmonary blood flow ( $P=$ $.001)$ and hemoglobin $(P=.02)$ and negatively correlated with systemic vascular resistance $(P=.003)$. It was not correlated with oxygen consumption $(P>.05)$.

Conclusions: Cerebral oxygen saturation decreased significantly in neonates during the early postoperative period after the Norwood procedure and was significantly influenced by systemic hemodynamic and metabolic events. As such, hemodynamic interventions to modify systemic oxygen transport may provide further opportunities to reduce the risk of cerebral ischemia and improve neurodevelopmental outcomes.

$\mathrm{T}$ There has been a dramatic reduction in mortality after surgery for complex congenital heart defects. Consequently, much attention is now being directed to neurologic outcomes among survivors. ${ }^{1}$ The incidence of measurable neurologic sequelae is as high as $25 \%$, including both early postoperative seizures ${ }^{2,3}$ and long-term neurodevelopmental impairment such as cognitive, attentional, behavioral, and neuromuscular disabilities. ${ }^{4-8}$ Studies on neurologic outcomes have largely focused on specific intraoperative risk factors, such as hemodilution, $\mathrm{pH}$ management, ${ }^{9}$ and deep hypothermic circulatory arrest. ${ }^{2-5,8,10}$ Others have reported preoperative reduction of cerebral blood flow and ischemic injury (in turn related to anatomic and functional features), being most severe in neonates with hypoplastic left heart syndrome. ${ }^{11-14}$ Postoperative hemodynamic instability may further affect 

Abbreviations and Acronyms
$\mathrm{CPB}=$ cardiopulmonary bypass
$\mathrm{DO}_{2}=$ oxygen delivery
$\mathrm{ERO}_{2}=$ oxygen extraction ratio
$\mathrm{ICU}=$ intensive care unit
NIRS $=$ near-infrared spectroscopy
$\mathrm{PaO}_{2}=$ arterial oxygen tension
Qp = pulmonary blood flow
Qs $=$ systemic blood flow
$\mathrm{ScO}_{2}=$ cerebral oxygen saturation
$\mathrm{SVR}=$ systemic vascular resistance
$\mathrm{VO}_{2}=$ oxygen consumption

moglobin saturation. ${ }^{22,23}$ It has been extensively used during $\mathrm{CPB}$ to determine the risk factors for poor cerebral perfusion. ${ }^{16,18,24}$ In the present study, we hypothesized that cerebral oxygen transport might be influenced by systemic hemodynamics and oxygen transport during the early postoperative period after the Norwood procedure. We used NIRS to continuously measure cerebral oxygen saturation $\left(\mathrm{ScO}_{2}\right)$ and respiratory mass spectrometry to continuously measure $\mathrm{VO}_{2}$ and to derive measurements of $\mathrm{Qp}$ and $\mathrm{Qs}$, $\mathrm{Do}_{2}$, and oxygen extraction ratio $\left(\mathrm{ERO}_{2}\right)$. We examined the effects of each of the systemic hemodynamic indices and oxygen transport variables on $\mathrm{ScO}_{2}$ during the first 72 hours after the Norwood procedure.

\section{Patients and Methods}

\section{Patients}

This study was approved by the Research Ethics Board at the Hospital for Sick Children, Toronto, Canada. Written informed consent was obtained from the parents of 16 neonates (14 boys, age range 4-16 days, median 7 days) undergoing the Norwood procedure between April 2004 and November, 2006. Patient demographics are shown in Table E1. Data from some of these patients were reported previously on systemic hemodynamics and oxygen transport early after the Norwood procedure. ${ }^{19,20}$

\section{Operative Procedure}

Neonates were intubated with a cuffed endotracheal tube (MicrocuffHeidelberg-Pediatric; Microcuff GmbH, Weinheim, Germany). General anesthesia was maintained with inhaled isoflurane, intravenous fentanyl, and pancuronium bromide. A standard Norwood procedure with regional cerebral circulation was used. All neonates had a 3.5-mm right modified Blalock-Taussig shunt with the distal anastomosis placed centrally on the intramediastinal pulmonary artery. CPB management consisted of a target flow of 125 $\mathrm{mL} \cdot \min ^{-1} \cdot \mathrm{kg}^{-1}$ and a hematocrit value of $25 \%$ to $30 \%$ with modified $\mathrm{pH}$-stat blood gas management for uniform cooling $\left(18^{\circ} \mathrm{C}-20^{\circ} \mathrm{C}\right)$ at the esophageal site. Selected cerebral perfusion was performed in all neonates at pump flows of 30 to $35 \mathrm{~mL}$. $\min ^{-1} \cdot \mathrm{kg}^{-1}$. All neonates received aprotinin $1.7 \times 106 \mathrm{KIU} / \mathrm{m}^{2}$ and methylprednisolone $10 \mathrm{mg} / \mathrm{kg}$ before CPB. Phenoxybenzamine $0.25 \mathrm{mg} / \mathrm{kg}$ was added to the pump prime. Separation from CPB occurred after initiation of infusions of milrinone $(0.66 \mu \mathrm{g}$. $\left.\min ^{-1} \cdot \mathrm{kg}^{-1}\right)$ and dopamine $\left(5 \mu \mathrm{g} \cdot \min ^{-1} \cdot \mathrm{kg}^{-1}\right)$. Modified ultrafiltration was used in all neonates immediately after separation from CPB. A pulmonary venous line was inserted into the orifice of the right upper pulmonary vein. The sternal incision was left open routinely in all the patients.

\section{Critical Care}

Infants received time-cycled pressure control/pressure support ventilation. Sedation and analgesia were given as a continuous intravenous infusion of morphine $\left(20-40 \mu \mathrm{g} \cdot \mathrm{h}^{-1} \cdot \mathrm{kg}^{-1}\right)$, intermittent injections of lorazepam $(0.1 \mathrm{mg} / \mathrm{kg})$, and pancuronium $(0.1$ $\mathrm{mg} / \mathrm{kg}$ ). Pancuronium was discontinued when the patient achieved satisfactory hemodynamic stability.

The central esophageal temperature was monitored continuously and maintained at $36^{\circ} \mathrm{C}-37^{\circ} \mathrm{C}$. Vasoactive agents (milrinone,

(NIRS) provides a noninvasive, continuous method to monitor regional tissue oxyhe- 

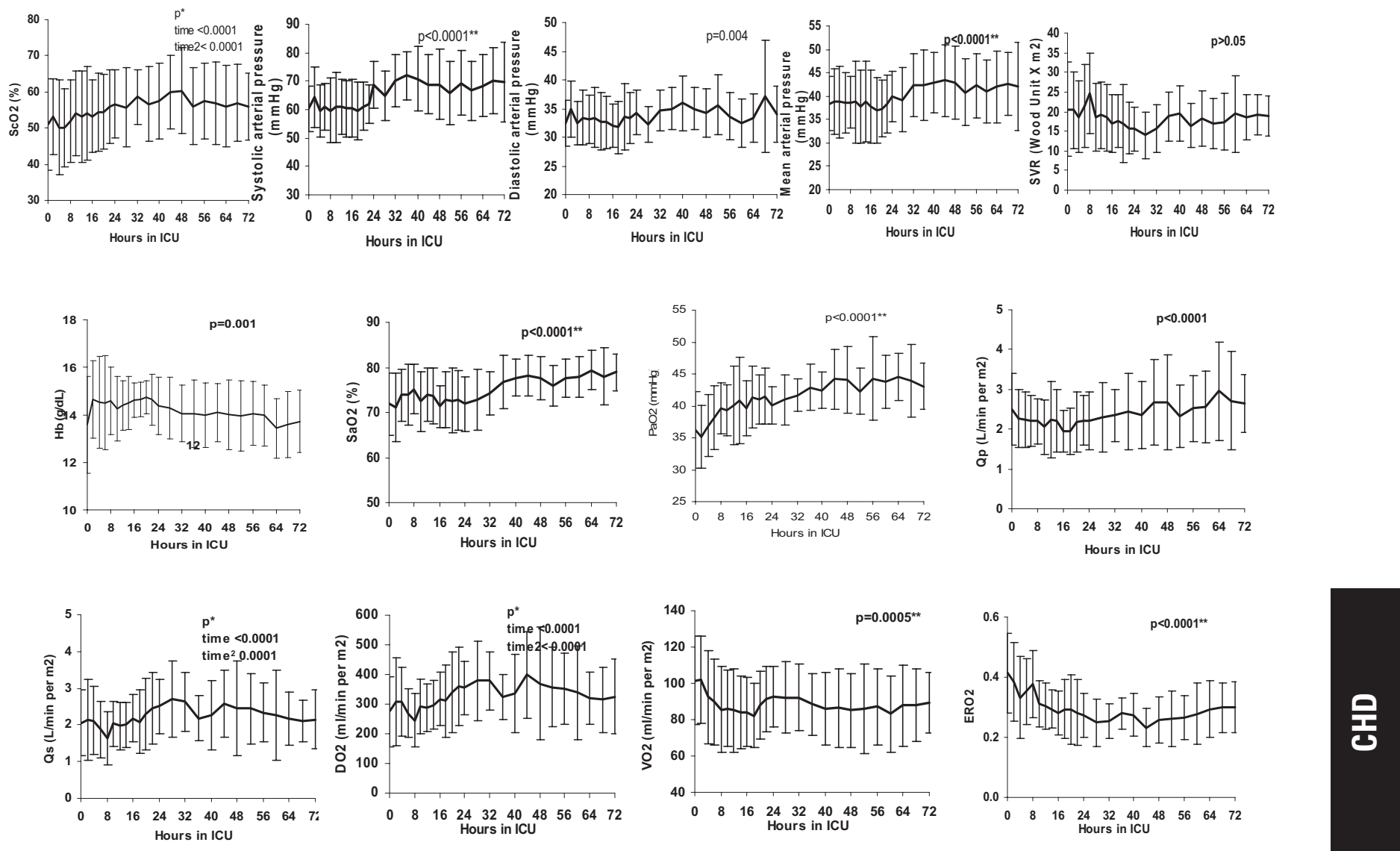

Figure 1. Mean $\pm \mathrm{SD}$ values of cerebral oxygen saturation $\left(\mathrm{Sco}_{2}\right)$ and hemodynamics including systolic, diastolic, and mean arterial pressures, systemic vascular resistance (SVR), arterial oxygen saturation ( $\mathrm{SaO}_{2}$ ), arterial partial oxygen pressure $\left(\mathrm{PaO}_{2}\right)$, hemoglobin $(\mathrm{Hb})$, pulmonary ( $\mathrm{Op}$ ) and systemic blood flows (Os), and oxygen transport including systemic oxygen consumption $\left(\mathrm{Vo}_{2}\right)$, oxygen delivery $\left(\mathrm{Do}_{2}\right)$, and oxygen extraction ratio $\left(E \mathrm{RO}_{2}\right)$ during the first 72 hours after arrival in the intensive care unit. *After polynomial transformation, with time indicating the coefficient of the early trend, and time $^{2}$ indicating the later trend. **Data were entered after logarithmic transformation.

dopamine, phenoxybenzamine, and vasopressin) and ventilatory settings were adjusted according to our standard protocol to achieve arterial carbon dioxide tension around 45 to $50 \mathrm{~mm} \mathrm{Hg}$ and $\mathrm{pH} 7.3$ to 7.4 , mean arterial blood pressure 40 to $45 \mathrm{~mm} \mathrm{Hg}$ with systolic pressure in the range of 55 to $65 \mathrm{~mm} \mathrm{Hg}$, arterial oxygen saturation $70 \%$ to $80 \%$, and superior vena caval saturation of $44 \%$ to $55 \% .^{25}$ Intravenous volume infusions (5\% albumin or blood) were given to maintain filling pressures of 7 to $10 \mathrm{~mm} \mathrm{Hg}$. Transfusions were given for a hemoglobin of less than $14 \mathrm{mg} / \mathrm{dL}$, and hemoglobin was generally maintained between 14 and 16 $\mathrm{mg} / \mathrm{dL}$ (Figure 1).

\section{Methods of Measurements}

$\mathrm{ScO}_{2}$. A NIRS probe, consisting of a near-infrared light emitter optode and a receiver optode with a distance of $5 \mathrm{~cm}$, was placed on the patient's midline forehead. The recordings were monitored by a dual-detector device (Somanetics INVOS 5100A, Troy, Mich) and recorded at 1-minute intervals.
$\boldsymbol{V o}_{2} \cdot \mathrm{VO}_{2}$ was measured continuously with an AMIS2000 respiratory mass spectrometer (Innovision A/S, Odense, Denmark). This is a sensitive and accurate method that allows simultaneous measurements of multiple gas fractions. The detailed methodology used in this protocol has been published previously by our group. ${ }^{20}$

Calculations of hemodynamic and oxygen transport variables. Blood samples were taken from the arterial line, superior vena cava, and pulmonary vein lines for the measurements of blood gases and saturations. Qp and Qs were then calculated by the direct Fick method:

$$
\begin{aligned}
& \mathrm{Qp}=\mathrm{VO}_{2} /\left(\mathrm{CpvO}_{2}-\mathrm{CaO}_{2}\right) \\
& \mathrm{Qs}=\mathrm{Vo}_{2}\left(\mathrm{CaO}_{2}-\mathrm{CVO}_{2}\right)
\end{aligned}
$$

Systemic vascular resistance (SVR) was calculated by the following equation:

$$
\mathrm{SVR}=(\mathrm{MAP}-\mathrm{MVP}) / \mathrm{Qs}
$$


$\mathrm{DO}_{2}$ and $\mathrm{ERO}_{2}$ were calculated by standard equations:

$$
\begin{aligned}
\mathrm{Do}_{2} & =\mathrm{Qs} \times \mathrm{CaO}_{2} \\
\mathrm{ERO}_{2} & =\mathrm{VO}_{2} / \mathrm{Do}_{2}
\end{aligned}
$$

where $\mathrm{CaO}_{2}, \mathrm{CpvO}_{2}$, and $\mathrm{CvO}_{2}$ indicate systemic arterial (which is pulmonary arterial), pulmonary venous, and superior vena cava oxygen contents, respectively; MAP and MVP indicate the mean arterial and superior vena cava pressures. All values were indexed to body surface area as calculated before the operation.

\section{Study Protocol}

$\mathrm{ScO}_{2}$ was continuously monitored after anesthesia introduction, during the operation, and 72 hours after the operation. Intraoperative clinical data (including esophageal temperature, systemic arterial blood pressure, and blood gases) were collected before the operation as baseline, before selective cerebral perfusion (CPB cooling), during selective cerebral perfusion, before separation from CPB (CPB rewarming), and at the end of the operation. Postoperative study recordings were prospectively performed during the first 72 hours after arrival in the ICU. Values of hemodynamic and oxygen transport variables and central body temperature were collected at 2-hour intervals during the first 24 hours and at 4-hour intervals in hours 25 through 72 . Sampling was avoided if a change in sedation, paralysis, ventilatory, or hemodynamic treatment was made within 15 minutes. The treating physicians were blinded to NIRS values during the postoperative period.

\section{Data Analysis}

Data are expressed as mean \pm standard deviation. Mixed linear regression analysis for repeated measures was used to determine the nature of any time trend of the measures over the 72-hour study period. For some measures, various transformations of time (logarithmic and polynomial) were tested regarding the best fit for the time course. Correlations between the variables were sought also using mixed linear regression analysis for repeated measures. The extent of correlation was indicated by the intercept, parameter estimate, and $P$ value. Further comparisons of the extents of correlations between the 2 periods in the first 24 hours and the following 48 hours were made and indicated by the parameter estimates of the interactions of time period and the variables and $P$ values. All data analyses were performed with SAS statistical software version 9.2 (SAS Institute, Inc, Cary, NC).

\section{Results}

\section{Patients}

There was no incidence of circulatory collapse or death during the study period. All neonates survived to hospital discharge except for one who died of cardiac failure on the 25 th postoperative day (patient 13). Complete data sets were collected in all neonates for 72 hours except in one (patient 8) owing to weaning from mechanical ventilation at 48 hours. The standard neonatal physical examination at the time of discharge did not demonstrate abnormal neurologic findings.

\section{Intraoperative Changes of $\mathrm{Sco}_{2}$}

$\mathrm{ScO}_{2}$ values differed markedly between the different periods of perfusion and surgical repair. Preoperative baseline $\mathrm{ScO}_{2}$ was $66 \% \pm 12 \% . \mathrm{ScO}_{2}$ increased to $88 \% \pm 6 \%$ at the end of cooling and was $90 \% \pm 7 \%$ during selective cerebral perfusion. It decreased to $64 \% \pm 9 \%$ during rewarming, and further to $54 \% \pm 6 \%$ after separation from $\mathrm{CPB}$, significantly lower than the preoperative baseline level $(P=.02)$.

\section{Postoperative Changes of $\mathrm{Sco}_{2}$ and Systemic Hemodynamic and Oxygen Transport Variables}

Table E2 and Figure 1 show the results of $\mathrm{ScO}_{2}$ and its temporal relationship with systemic hemodynamic, and oxygen transport variables during the 72 hours after arrival in the ICU. All the variables showed substantial intraindividual and interindividual variations over the study period, with marked differences in the time course and extent of change.

$\mathrm{Sco}_{2} \cdot \mathrm{ScO}_{2}$ further decreased to $51 \% \pm 13 \%$ on arrival in the ICU and remained at the low level in the initial 8 hours. Over the first 72 hours, $\mathrm{ScO}_{2}$ was significantly related to time in a complex polynomial function, with an increase in the first 48 hours $(P<.0001)$ and a subsequent small but significant decrease in 48 to 72 hours $(P<.0001)$. The mean value of $\mathrm{ScO}_{2}$ at 72 hours was $56 \% \pm 9 \%$, significantly lower than the preoperative baseline level $(P=.02)$. When all data were pooled together, the values ranged from $27 \%$ to $79 \%$, with $28 \%$ of the measurements lower than the reported critical level of $48 \% .^{26-28}$

Systemic hemodynamics and oxygen transport. Systolic and mean arterial pressures were significantly related to time after a logarithmic transformation, being initially low in the first 24 hours, followed by a rapid increase between 24 and 48 hours, and remained at that level thereafter $(P<.0001$ for both). Diastolic arterial pressure significantly and linearly increased over the study period $(P=$ .004). SVR was significantly related to time in a complex polynomial function, being initially high in the first 8 hours, followed by a rapid decrease in the first 24 hours $(P<$ $.0001)$, and a subsequent small but significant increase $(P=$ .0001). Hemoglobin showed a small linear decrease over time $(P<.0001) . \mathrm{SaO}_{2}$ and arterial oxygen tension $\left(\mathrm{PaO}_{2}\right)$ were significantly related to time after logarithmic transformation, with a rapid increase in the first 24 hours and thereafter a slow increase $(P<.0001)$. Qp showed a linear significant increase over time $(P<.0001)$. Qs and $\mathrm{Do}_{2}$ were significantly related to time in a complex polynomial function, with an initial rapid increase in the first 24 hours followed by a slow increase $(P<.0001$ for both), and a subsequent small but significant decrease at around 28 hours ( $P=.0001$ for Qs and $P<.0001$ for $\mathrm{Do}_{2}$ ). $\mathrm{Vo}_{2}$ and $\mathrm{ERo}_{2}$ were significantly related to time after logarithmic transformation, showed a rapid decrease in the first 8 hours, and a 

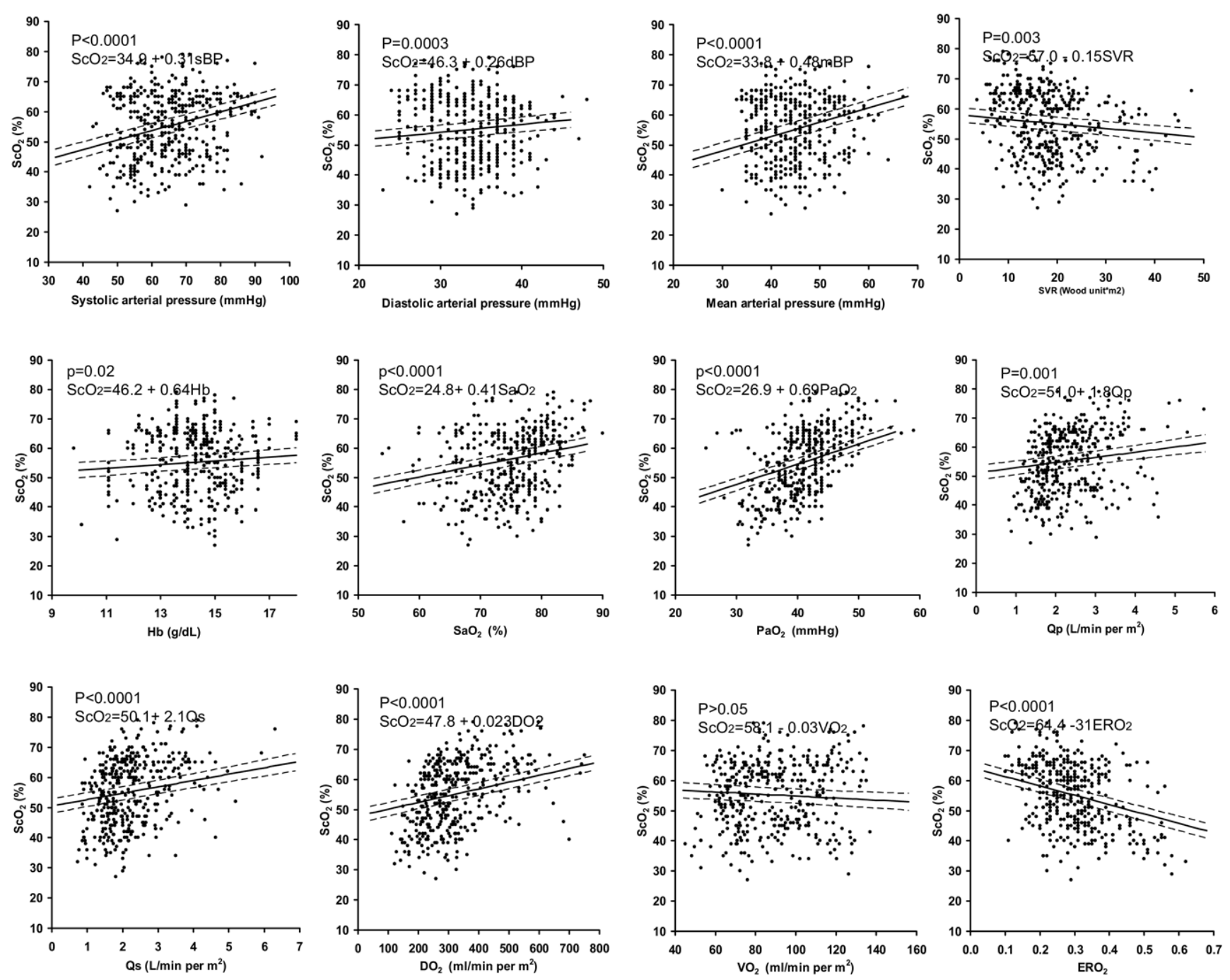

Figure 2. Correlations between cerebral oxygen saturation $\left(\mathrm{ScO}_{2}\right)$ and systemic hemodynamic and oxygen transport variables of systolic, diastolic, and mean arterial pressures, systemic vascular resistance (SVR), arterial oxygen saturation $\left(\mathrm{SaO}_{2}\right)$, arterial partial oxygen pressure $\left(\mathrm{PaO}_{2}\right)$, Hemoglobin ( $\left.\mathrm{Hb}\right)$, pulmonary (Op) and systemic blood flows $(\mathrm{Qs})$, systemic oxygen consumption $\left(\mathrm{Vo}_{2}\right)$, oxygen delivery $\left(\mathrm{Do}_{2}\right)$, and oxygen extraction ratio $\left(E \mathrm{Eo}_{2}\right)$ in neonates during the first $\mathbf{7 2}$ hours after arrival in the intensive care unit (ICU).

subsequent slow decrease $\left(P=.0005\right.$ for $\mathrm{Vo}_{2}$, and $P<$ .0001 for $\mathrm{ERO}_{2}$ ).

Correlations of $\mathrm{Sco}_{2}$ With Systemic Hemodynamics and Oxygen Transport

The statistical analysis results of the correlations between $\mathrm{ScO}_{2}$ and systemic hemodynamics and oxygen transport during the whole study period are seen in Table E3 and Figure 2.

$\mathrm{ScO}_{2}$ was closely and positively correlated with systolic, diastolic, and mean arterial pressures (parameter estimate $0.31,0.26$, and 0.48 , respectively; $P<.0001, P=.0003$, and $P<.0001$, respectively) and with $\mathrm{SaO}_{2}$ and $\mathrm{PaO}_{2}$ (parameter estimate 0.41 and 0.69 , respectively; $P<.0001$ for both). $\mathrm{ScO}_{2}$ was also closely and negatively correlated with $\mathrm{ERO}_{2}$ (parameter estimate $-31.0 ; P<.0001$ ). It was moderately and positively correlated with Qs (parameter estimate $2.1 ; P<.0001$ ) and $\mathrm{Do}_{2}$ (parameter estimate $0.023 ; P<.0001)$. It was weakly but significantly and positively correlated with $\mathrm{Qp}$ (parameter estimate $1.8 ; P=$ .001 ) and negatively with SVR (parameter estimate -0.15 ; $P=.003)$. It was not correlated with $\mathrm{VO}_{2}(P>.05)$.

Additionally, $\mathrm{PaO}_{2}$ and $\mathrm{SaO}_{2}$ were weakly correlated with Qp (parameter estimate $0.05 ; P<.0001$ for both), Qp/Qs 
(parameter estimate 0.03 and 0.04 , respectively; $P<.0001$ for both), and $\mathrm{Do}_{2}$ (parameter estimate 3.7, $P=.002$ for $\mathrm{PaO}_{2}$; parameter estimate $-0.16 ; P>.05$ for $\mathrm{SaO}_{2}$ ). The extents of correlations of $\mathrm{ScO}_{2}$ with hemodynamics and oxygen transport variables were not significantly different between the period of the first 24 hours and that of the later period $(P>.05$ for all $)$.

\section{Discussion}

This is the first study to examine the consequences of postoperative systemic hemodynamics and oxygen transport on cerebral oxygenation in neonates with hypoplastic left heart syndrome after the Norwood procedure. We found that $\mathrm{ScO}_{2}$ fell during the first 8 hours after surgery and then increased in neonates during the first 72 hours after the Norwood procedure. Critically low levels of $\mathrm{ScO}_{2}$ occurred frequently. The changes in $\mathrm{ScO}_{2}$ were significantly related to the changes in systemic hemodynamics and oxygen transport variables.

NIRS was used to estimate cerebral oxygenation in our study. The dual-path length device we used measures the percentage of oxyhemoglobin to total hemoglobin in the mixture of arteries, capillaries, and veins in a slice of tissue approximately 1.5 to $2.5-\mathrm{cm}$ deep. ${ }^{22}$ Because the predominant venous portion may account for approximately $70 \%$ to $80 \%$ in NIRS signals, ${ }^{29}$ the changes in $\mathrm{ScO}_{2}$ can estimate the cerebral flow-metabolism relationships. In heavily sedated subjects, as in these neonates, in whom aerobic metabolism of the brain is relatively low and stable, $\mathrm{ScO}_{2}$ may act as surrogate for cerebral blood flow and $\mathrm{Do}_{2}$.

Evidence from adult humans ${ }^{26}$ and neonatal piglets ${ }^{28}$ indicates that aerobic metabolism may be impaired when $\mathrm{ScO}_{2}$ decreases below $44 \%$ to $47 \%$. In a recent study of neonates after the Norwood procedure, prolonged exposure to low postoperative $\mathrm{ScO}_{2}$ ( $<45 \%$ for $>180$ minutes) was associated with the development of ischemic lesions on magnetic resonance imaging. ${ }^{27}$ In our neonates, the preoperative baseline $\mathrm{ScO}_{2}$ was $66 \% \pm 12 \%$, similar to the range reported by Hoffman and associates. ${ }^{18}$ The intraoperative changes also showed a similar pattern. ${ }^{18} \mathrm{ScO}_{2}$ increased during cooling, was well maintained during selective cerebral perfusion, and decreased after rewarming and separation from bypass to be lower than preoperative baseline values, at an average of $54 \% \pm 6 \%$. There was a further decrease in $\mathrm{ScO}_{2}$ in the first 8 hours after arrival in the ICU. Despite the subsequent increase, at 72 hours $\mathrm{ScO}_{2}$ was still significantly lower than preoperative baseline levels.

This study shows that the vulnerable brain is dependent on unstable hemodynamics and oxygen transport seen in the early postoperative period after the Norwood procedure. $\mathrm{Do}_{2}$ is characteristically low and highly variable. Qs and $\mathrm{Do}_{2}$ are most depressed during the first 12 to 24 hours; at the same time, $\mathrm{VO}_{2}$ is high, further compounding the imbalance of oxygen transport. ${ }^{19,20}$ Thus the first 12 to 24 hours represents a critical period for not only cardiovascular but also neurologic morbidity. Low $\mathrm{ScO}_{2}$ was associated with depressed hemodynamics and impaired balance of oxygen transport, as seen in the low arterial blood pressure, $\mathrm{SaO}_{2}$, $\mathrm{PaO}_{2}, \mathrm{Qp}, \mathrm{Qs}$, and $\mathrm{Do}_{2}$ and a high $\mathrm{VO}_{2}$ and $\mathrm{ERO}_{2}$. Thereafter, $\mathrm{ScO}_{2}$ improved with the gradual recovery in hemodynamics and oxygen transport.

$\mathrm{ScO}_{2}$ showed wide interindividual and intraindividual variations throughout the study period $(27 \%-79 \%)$. The frequency of a critically low level $(<48 \%)$ was substantial, representing about $28 \%$ of all the measurements. Correlation analysis revealed that the changes in $\mathrm{ScO}_{2}$ were influenced by the different elements of systemic hemodynamics and oxygen transport measurements to different degrees. The close and positive correlation between $\mathrm{ScO}_{2}$ and $\mathrm{SaO}_{2}$ may be expected because of the intrinsic arterial contribution to the NIRS signals. An arterial contribution of $16 \% \pm$ $21 \%$ to the NIRS signals has been reported by Watzman and associates $^{29}$ in a group of children with congenital heart disease of varied arterial oxygen saturations. The explanation for the close positive correlation with $\mathrm{PaO}_{2}$ may be less clear-cut. Arterial hypoxemia is known to increase cerebral blood flow when $\mathrm{PaO}_{2}$ is reduced to less than 30 to $50 \mathrm{~mm}$ $\mathrm{Hg}$ in models of acute hypoxemia. ${ }^{30}$ This regulation may be impaired in subjects exposed to chronic hypoxemia ${ }^{31}$ and further compounded by anesthesia and hypothermic CPB. This may be the case in our patient population. Although speculative, with the loss of such compensation mechanism, a decrease in $\mathrm{PaO}_{2}$ may lead to a direct decrease in cerebral $\mathrm{Do}_{2}$. Arterial oxygenation has little impact on $\mathrm{Qp}$ and $\mathrm{Qp} / \mathrm{Qs}$ and little contribution to systemic $\mathrm{Do}_{2} \cdot{ }^{20}$ It does, however, appear to have significant impact on cerebral $\mathrm{Do}_{2}$. Therefore, limiting arterial oxygenation as a means of favorably balancing the parallel circulations may be suboptimal, but may have an unnecessary detrimental impact on the brain. Indeed, the judicious use of inspired oxygen may be beneficial to cerebral oxygenation and metabolism without compromising systemic circulation. $\mathrm{ScO}_{2}$ was positively correlated with hemoglobin in these neonates. A positive correlation has been found between $\mathrm{ScO}_{2}$ and hemoglobin during mild-to-moderate hemodilution ${ }^{32,33}$ and is further supported in our data in subjects with relatively high levels of hemoglobin.

The intercorrelations of $\mathrm{ScO}_{2}$, systemic arterial pressure, SVR, and Qs are also important to note for these neonates. $\mathrm{ScO}_{2}$ was significantly and positively correlated with systolic, diastolic, and mean arterial pressures. This may indicate impaired cerebrovascular autoregulation or a pressurepassive cerebral circulation after $\mathrm{CPB} .^{34,35}$ The low diastolic pressure in the presence of a Blalock-Taussig shunt may further render the brain vulnerable to hypoper- 
fusion or hypoxic insult. Loss of cerebrovascular autoregulation and low diastolic arterial pressure have previously been shown to be risk factors for the occurrence of severe periventricular leukomalacia in premature infants ${ }^{34}$ and in neonates after cardiac surgery. ${ }^{16}$ Interestingly, the close and positive interrelationships between $\mathrm{ScO}_{2}$ and arterial pressure and, in turn, between arterial pressure and SVR did not necessarily lead to positive correlation between $\mathrm{ScO}_{2}$ and SVR. In fact, $\mathrm{ScO}_{2}$ was negatively and significantly correlated with SVR. This is largely due to the negative correlation between SVR and Qs and $\mathrm{Do}_{2}$; Qs and $\mathrm{Do}_{2}$ were significantly and positively correlated with $\mathrm{ScO}_{2}$.

It is our routine management of these neonates to use phenoxybenzamine and milrinone to sustain a relatively low SVR and to maintain an adequate Qs and $\mathrm{Do}_{2} \cdot{ }^{25,36}$ The current study shows that this approach may also be beneficial to improve cerebral oxygenation. Furthermore, phenoxybenzamine can cross the blood-brain barrier and may have a direct and important effect on reducing cerebral vascular resistance. ${ }^{37}$ Phenoxybenzamine may also contribute to maintaining cerebral blood flow during hypotension induced by bleeding ${ }^{38}$ and enhance cerebrovascular response to carbon dioxide. ${ }^{39}$ These properties of phenoxybenzamine are appealing in the care of neonates after the Norwood operation, in whom the goal is to optimize both systemic and cerebral oxygen transport. Further studies are necessary to quantify the potential effect of redistribution of blood flow between cerebral and systemic vascular beds caused by this and other medications.

The lack of correlation between $\mathrm{ScO}_{2}$ and $\mathrm{VO}_{2}$ is likely due to the deep sedation used to minimize cerebral $\mathrm{VO}_{2}$. Nonetheless, the improvement in $\mathrm{ScO}_{2}$ was most pronounced when $\mathrm{VO}_{2}$ was most rapidly decreased. As we have demonstrated, $\mathrm{VO}_{2}$ is the most important contributor to the improvement in the balance of oxygen transport during the early hours after the Norwood procedure. ${ }^{22}$ The close and negative correlation between $\mathrm{ScO}_{2}$ and $\mathrm{ERO}_{2}$ indicates the important influence of the balance of systemic oxygen transport on cerebral oxygenation during the early postoperative period after the Norwood procedure. Strategies to limit $\mathrm{VO}_{2}$ may therefore improve overall oxygen balance and may be particularly relevant to neonates after the Norwood procedure, in whom $\mathrm{Do}_{2}$ is tenuous.

Of note, whereas the low $\mathrm{ScO}_{2}$ during the first 24 hours was associated with depressed systemic hemodynamics and impaired balance of oxygen transport, the influence of the systemic hemodynamics and oxygen transport variables on $\mathrm{SCO}_{2}$ was of equal significance between the period of the first 24 hours and the following 48 hours. This may indicate that cerebral oxygen transport is vulnerable to systemic hemodynamic and oxygen transport fluctuations during the early days after the Norwood procedure.

\section{Limitations}

The superior vena cava was used to measure systemic venous saturation for the calculations of $\mathrm{Qs}$ and $\mathrm{Do}_{2}$. This measure does not account for potential differences in the inferior vena cava saturation. ${ }^{40}$ Conversely, it could be argued that by sampling upper body venous saturation, we have a more representative measurement, incorporating cerebral blood flow.

NIRS was used to estimate cerebral oxygenation in our study. As mentioned earlier, NIRS measures oxygen saturation in the mixture of arteries, capillaries, and veins in a small part of underlining cerebral tissue and thus may not precisely reflect overall balance of cerebral oxygen transport. The value of the critically low $\mathrm{ScO}_{2}$ was derived from subjects with biventricular circulation ${ }^{26-28}$ and may not be generalizable to subjects with single ventricle and parallel circulations. Further assessments of cerebral oxygen and lactate extractions with a jugular bulb venous probe may be more precise to reflect cerebral oxygen transport. This, in combination with electroencephalography and cerebral magnetic resonance imaging, will provide further information about the influence of postoperative hemodynamics and oxygen transport on cerebral oxygen transport, ischemic injuries, and functional outcomes in this high-risk group of neonates.

\section{Conclusions}

$\mathrm{ScO}_{2}$ decreases significantly in neonates during the early postoperative period after the Norwood procedure. A critically low level of $\mathrm{ScO}_{2}$ occurs frequently and is significantly influenced by the systemic hemodynamic instability and the imbalance of systemic oxygen transport. Interventions to optimize hemodynamic stability and to achieve an adequate balance of oxygen transport, including maintaining a low SVR and adequate Qs and $\mathrm{Do}_{2}$, a relatively high hemoglobin, and in addition, judicious use of high inspired oxygen, may provide further opportunities to reduce the risk of cerebral ischemic injury and improve neurodevelopmental outcomes. Future studies correlating systemic hemodynamics and oxygen transport and cerebral oxygen transport to functional neurologic outcome may yield important insights of neurologic injury.

\section{References}

1. Wernovsky G. Current insights regarding neurological and developmental abnormalities in children and young adults with complex congenital cardiac disease. Cardiol Young. 2006;16(Suppl 1):92-104.

2. Clancy RR, McGaurn SA, Goin JE, Hirtz DG, Norwood WI, Gaynor JW, et al. Allopurinol neurocardiac protection trial in infants undergoing heart surgery using deep hypothermic circulatory arrest. Pediatrics. 2001;108:61-70.

3. Newburger JW, Jonas RA, Wernovsky G, Wypij D, Hickey PR, Kuban $\mathrm{KC}$, et al. A comparison of the perioperative neurologic effects of hypothermic circulatory arrest versus low-flow cardiopulmonary bypass in infant heart surgery. $N$ Engl J Med. 1993;329:1057-64. 
4. Bellinger DC, Jonas RA, Rappaport LA, Wypij D, Wernovsky G, Kuban KC, et al. Developmental and neurologic status of children after heart surgery with hypothermic circulatory arrest or low-flow cardiopulmonary bypass. $N$ Engl J Med. 1995;332:549-55.

5. Bellinger DC, Wypij D, Kuban KC, Rappaport LA, Hickey PR, Wernovsky G, et al. Developmental and neurological status of children at 4 years of age after heart surgery with hypothermic circulatory arrest or low-flow cardiopulmonary bypass. Circulation. 1999;100:526-32.

6. Mahle WT, Clancy RR, Moss EM, Gerdes M, Jobes DR, Wernovsky G. Neurodevelopmental outcome and lifestyle assessment in schoolaged and adolescent children with hypoplastic left heart syndrome. Pediatrics. 2000;105:1082-9.

7. Wernovsky G, Stiles KM, Gauvreau K, Gentles TL, duPlessis AJ, Bellinger DC, et al. Cognitive development after the Fontan operation. Circulation. 2000;102:883-9.

8. Wypij D, Newburger JW, Rappaport LA, duPlessis AJ, Jonas RA, Wernovsky G, et al. The effect of duration of deep hypothermic circulatory arrest in infant heart surgery on late neurodevelopment: the Boston Circulatory Arrest Trial. J Thorac Cardiovasc Surg. 2003;126: 1397-403.

9. Duebener LF, Hagino I, Sakamoto T, Mime LB, Stamm C, Zurakowski D, et al. Effects of $\mathrm{pH}$ management during deep hypothermic bypass on cerebral microcirculation: alpha-stat versus pH-stat. Circulation. 2002;106(12 Suppl 1):I103-8.

10. Gaynor JW, Nicolson SC, Jarvik GP, Wernovsky G, Montenegro LM, Burnham NB, et al. Increasing duration of deep hypothermic circulatory arrest is associated with an increased incidence of postoperative electroencephalographic seizures. J Thorac Cardiovasc Surg. 2005; 130:1278-86

11. Kurth CD, Steven JL, Montenegro LM, Watzman HM, Gaynor JW, Spray TL, et al. Cerebral oxygen saturation before congenital heart surgery. Ann Thorac Surg. 2001;72:187-92.

12. Licht DJ, Wang J, Silvestre DW, Nicolson SC, Montenegro LM, Wernovsky G, et al. Preoperative cerebral blood flow is diminished in neonates with severe congenital heart defects. J Thorac Cardiovasc Surg. 2004;128:841-9.

13. Glauser TA, Rorke LB, Weinberg PM, Clancy RR. Acquired neuropathologic lesions associated with the hypoplastic left heart syndrome. Pediatrics. 1990;85:991-1000.

14. Glauser TA, Rorke LB, Weinberg PM, Clancy RR. Congenital brain anomalies associated with the hypoplastic left heart syndrome. Pediatrics. 1990;85:984-90.

15. Newburger JW, Wypij D, Bellinger DC, du Plessis AJ, Kuban KC, Rappaport LA, et al. Length of stay after infant heart surgery is related to cognitive outcome at age 8 years. J Pediatr. 2003;143:67-73.

16. Galli KK, Zimmerman RA, Jarvik GP, Wernovsky G, Kuypers MK, Clancy RR, et al. Periventricular leukomalacia is common after neonatal cardiac surgery. J Thorac Cardiovasc Surg. 2004;127:692-704.

17. Mahle WT, Tavani F, Zimmerman RA, Nicolson SC, Galli KK, Gaynor JW, et al. An MRI study of neurological injury before and after congenital heart surgery. Circulation. 2002;106(12 Suppl 1):I109-14.

18. Hoffman GM, Stuth EA, Jaquiss RD, Vanderwal PL, Staudt SR, Troshynski TJ, et al. Changes in cerebral and somatic oxygenation during stage 1 palliation of hypoplastic left heart syndrome using continuous regional cerebral perfusion. J Thorac Cardiovasc Surg. 2004;127:223-33.

19. Li J, Zhang G, Holtby HM, McCrindle BW, Cai S, Humpl T, et al. Inclusion of oxygen consumption improves the accuracy of arterial and venous oxygen saturation interpretation after the Norwood procedure. J Thorac Cardiovasc Surg. 2006;131:1099-107.

20. Li J, Zhang G, McCrindle BW, Holtby H, Humpl T, Cai S, et al. Profiles of hemodynamics and oxygen transport derived by using continuous measured oxygen consumption after the Norwood procedure. J Thorac Cardiovasc Surg. 2007;133:441-8.
21. Hoffman GM, Mussatto KA, Brosig CL, Ghanayem NS, Musa N, Fedderly RT, et al. Systemic venous oxygen saturation after the Norwood procedure and childhood neurodevelopmental outcome. J Thorac Cardiovasc Surg. 2005;130:1094-100.

22. Jobsis FF. Noninvasive, infrared monitoring of cerebral and myocardial oxygen sufficiency and circulatory parameters. Science. 1977;198: 1264-7.

23. Wyatt JS, Cope M, Delpy DT, Wray S, Reynolds EO. Quantification of cerebral oxygenation and haemodynamics in sick newborn infants by near infrared spectrophotometry. Lancet. 1986;2:1063-6.

24. Andropoulos DB, Stayer SA, McKenzie ED, Fraser CD Jr. Novel cerebral physiologic monitoring to guide low-flow cerebral perfusion during neonatal aortic arch reconstruction. J Thorac Cardiovasc Surg. 2003; 125:491-9.

25. De Oliveira NC, Van Arsdell GS. Practical use of alpha blockade strategy in the management of hypoplastic left heart syndrome following stage one palliation with a Blalock-Taussig shunt. Semin Thorac Cardiovasc Surg Pediatr Card Surg Annu. 2004;7:11-15.

26. Levy WJ, Levin S, Chance B. Near-infrared measurement of cerebra oxygenation. Correlation with electroencephalographic ischemia during ventricular fibrillation. Anesthesiology. 1995;83:738-46.

27. Dent CL, Spaeth JP, Jones BV, Schwartz SM, Glauser TA, Hallinan B, et al. Brain magnetic resonance imaging abnormalities after the Norwood procedure using regional cerebral perfusion. $J$ Thorac Cardiovasc Surg. 2006;131:190-7.

28. Kurth CD, Levy WJ, McCann J. Near-infrared spectroscopy cerebral oxygen saturation thresholds for hypoxia-ischemia in piglets. J Cereb Blood Flow Metab. 2002;22:335-41.

29. Watzman HM, Kurth CD, Montenegro LM, Rome J, Steven JM Nicolson SC. Arterial and venous contributions to near-infrared cerebral oximetry. Anesthesiology. 2000;93:947-53.

30. Gray IG, Mitra SK, Nisbet HI, Aspin N, Creighton RE. Cerebral blood flow in hypoxemic anesthetized dogs. Anesth Analg. 1971;50:594-608.

31. Longo LD, Hull AD, Long DM, Pearce WJ. Cerebrovascular adaptations to high-altitude hypoxemia in fetal and adult sheep. Am J Physiol. 1993;264(1 Pt 2):R65-72.

32. Yoshitani K, Kawaguchi M, Iwata M, Sasaoka N, Inoue S, Kurumatani $\mathrm{N}$, et al. Comparison of changes in jugular venous bulb oxygen saturation and cerebral oxygen saturation during variations of haemoglobin concentration under propofol and sevoflurane anaesthesia. $\mathrm{Br} \mathrm{J}$ Anaesth. 2005;94:341-6.

33. Torella F, McCollum CN. Regional haemoglobin oxygen saturation during surgical haemorrhage. Minerva Med. 2004;95:461-7.

34. Tsuji M, Saul JP, du Plessis A, Eichenwald E, Sobh J, Crocker R, et al. Cerebral intravascular oxygenation correlates with mean arterial pressure in critically ill premature infants. Pediatrics. 2000;106: 625-32.

35. Bassan H, Gauvreau K, Newburger JW, Tsuji M, Limperopoulos C, Soul JS, et al. Identification of pressure passive cerebral perfusion and its mediators after infant cardiac surgery. Pediatr Res. 2005;57:35-41.

36. De Oliveira NC, Ashburn DA, Khalid F, Burkhart HM, Adatia IT, Holtby HM, et al. Prevention of early sudden circulatory collapse after the Norwood operation. Circulation. 2004;110(11 Suppl 1):II133-8.

37. Muravchick S, Bergofsky EH. Adrenergic receptors and vascular resistance in cerebral circulation of the cat. J Appl Physiol. 1976;40: 797-804.

38. Hamar J, Kovach AG, Reivich M, Nyary I, Durity F. Effect of phenoxybenzamine on cerebral blood flow and metabolism in the baboon during hemorrhagic shock. Stroke. 1979;10:401-7.

39. Izumi Y, Fukuuchi Y, Imai A, Isozumi K. Alpha-adrenergic blockade with phenoxybenzamine enhances cerebrovascular $\mathrm{CO} 2$ reactivity. Keio J Med. 1993;42:60-3.

40. Uusaro A, Ruokonen E, Takala J. Splanchnic oxygen transport after cardiac surgery: evidence for inadequate tissue perfusion after stabilization of hemodynamics. Intensive Care Med. 1996;22:26-33. 
TABLE E1. Clinical data for the 16 neonates

\begin{tabular}{|c|c|c|c|c|c|c|c|c|}
\hline Patient & Age (d) & Weight (kg) & BSA $\left(\mathrm{m}^{2}\right)$ & CPB (min) & ACC (min) & $\begin{array}{l}\text { Circulatory } \\
\text { arrest (min) }\end{array}$ & $\begin{array}{c}\text { Cerebral } \\
\text { perfusion (min) }\end{array}$ & Diagnosis \\
\hline 1 & 4 & 3.7 & 0.25 & 151 & 100 & 35 & 53 & HLHS, AS, MS \\
\hline 2 & 16 & 3.5 & 0.24 & 133 & 39 & 34 & 0 & $\begin{array}{l}\text { HLHS, AS, MS, endocardial } \\
\text { fibroelastosis of LV }\end{array}$ \\
\hline 3 & 7 & 4.2 & 0.27 & 122 & 62 & 3 & 60 & HLHS, AS, MS \\
\hline 4 & 12 & 3.5 & 0.23 & 165 & 75 & 13 & 59 & DILV, TGA \\
\hline 5 & 6 & 3.5 & 0.23 & 172 & 82 & 9 & 70 & HLHS, AA, MA \\
\hline 6 & 7 & 4.0 & 0.25 & 167 & 64 & 17 & 44 & HLHS, AS, MS \\
\hline 7 & 6 & 2.9 & 0.20 & 142 & 62 & 1 & 62 & HLHS, AS, MS \\
\hline 8 & 9 & 3.6 & 0.24 & 109 & 50 & 4 & 44 & HLHS, AS, MS \\
\hline 9 & 7 & 2.8 & 0.19 & 66 & 59 & 17 & 20 & HLHS, AS, MS \\
\hline 10 & 5 & 2.5 & 0.18 & 170 & 126 & 46 & 60 & HLHS, AS, MS \\
\hline 11 & 4 & 4.2 & 0.27 & 124 & 99 & 44 & 49 & HLHS, AA, MA TAPVC \\
\hline 12 & 5 & 3.9 & 0.26 & 98 & 50 & 12 & 37 & HLHS, AA, MA \\
\hline 13 & 4 & 3.1 & 0.21 & 134 & 67 & 8 & 58 & HLHS, AA, MA \\
\hline 14 & 7 & 3.2 & 0.21 & 164 & 66 & 9 & 54 & $\begin{array}{l}\text { TA, TGA, hypoplastic aortic } \\
\text { arch }\end{array}$ \\
\hline 15 & 10 & 3.4 & 0.24 & 100 & 47 & 4 & 4 & HLHS, AA, MS \\
\hline 16 & 4 & 3.6 & 0.23 & 143 & 68 & 6 & 60 & HLHS, AA, MA \\
\hline
\end{tabular}

$A A$, Aortic atresia; $A S$, aortic stenosis; $A C C$, aortic crossclamp; $B S A$, body surface area; $C P B$, cardiopulmonary bypass; DILV, double-inlet left ventricle; $H L H S$, hypoplastic left heart syndrome; $L V$, left ventricle; $M A$, mitral atresia; $M S$, mitral stenosis; $T A P V C$, total anomalous pulmonary venous connection; $T G A$, transposition of great arteries; $T A$, tricuspid atresia.

TABLE E2. Statistical analysis results of the changes of $\mathrm{Sco}_{2}$, systemic hemodynamics, and oxygen transport in the 16 neonates during the 72-hour study period using mixed linear regression method

\begin{tabular}{|c|c|c|c|}
\hline Variables & Intercept & Parameter estimate & $P$ values \\
\hline \multirow{2}{*}{$\mathrm{ScO}_{2}(\%)^{*}$} & \multirow[t]{2}{*}{50} & Time 0.35 & $<.0001$ \\
\hline & & Time $^{2}-0.004$ & $<.0001$ \\
\hline SAP $(m m ~ H g) \dagger$ & 54 & 3.4 & $<.0001$ \\
\hline $\mathrm{DAP}(\mathrm{mm} \mathrm{Hg})$ & 33 & 0.03 & .004 \\
\hline $\mathrm{MAP}(\mathrm{mm} \mathrm{Hg}) \dagger$ & 40 & 1.6 & $<.0001$ \\
\hline \multirow[t]{2}{*}{ SVR (Wood unit $\left.\cdot \mathrm{m}^{2}\right)^{*}$} & \multirow[t]{2}{*}{21} & Time -0.23 & $<.0001$ \\
\hline & & Time $^{2} 0.003$ & .0001 \\
\hline $\mathrm{Hb}(\mathrm{g} / \mathrm{dL})$ & 14.5 & -0.009 & .001 \\
\hline $\mathrm{SaO}_{2}(\%) \dagger$ & 69 & 2.0 & $<.0001$ \\
\hline $\mathrm{PaO}_{2}(\mathrm{~mm} \mathrm{Hg}) \dagger$ & 33.5 & 2.5 & $<.0001$ \\
\hline$O p\left(L \cdot \min ^{-1} \cdot \mathrm{m}^{-2}\right)$ & 2.1 & 0.007 & $<.0001$ \\
\hline \multirow[t]{2}{*}{ Qs $\left(\mathrm{L} \cdot \min ^{-1} \cdot \mathrm{m}^{-2}\right)^{*}$} & \multirow[t]{2}{*}{1.9} & Time 0.03 & $<.0001$ \\
\hline & & Time $^{2}-0.0004$ & .0001 \\
\hline \multirow[t]{2}{*}{$\mathrm{Do}_{2}\left(\mathrm{~mL} \cdot \min ^{-1} \cdot \mathrm{m}^{-2}\right)^{*}$} & \multirow[t]{2}{*}{262} & Time 5.00 & $<.0001$ \\
\hline & & Time $^{2}-0.06$ & $<.0001$ \\
\hline $\mathrm{V}_{2}\left(\mathrm{~mL} \cdot \mathrm{min}^{-1} \cdot \mathrm{m}^{-2}\right) \dagger$ & 96 & -2.8 & .0005 \\
\hline $\mathrm{ERO}_{2} \dagger$ & 0.38 & -0.03 & $<.0001$ \\
\hline
\end{tabular}

$D A P$, Diastolic arterial pressure; $\mathrm{DO}_{2}$, systemic oxygen delivery; $E R 0_{2}$, oxygen extraction ratio; $\mathrm{Hb}$, hemoglobin; $M A P$, mean arterial pressure; $P a o_{2}$, arterial oxygen tension; $Q p$, pulmonary blood flow; $Q s$, systemic blood flow; $S a_{2}$, arterial oxygen saturation; $S A P$, systolic arterial pressure; $S \mathrm{CO}_{2}$, cerebral oxygen saturation; $S V R$, systemic vascular resistance; $V_{2}$, systemic oxygen consumption. *After polynomial transformation, with time indicating the coefficient of the early trend, and time ${ }^{2}$ indicating the later trend. †Data were entered after logarithmic transformation. 
TABLE E3. Statistical analysis results of the correlations of $\mathrm{ScO}_{2}$ as the dependent variable with the systemic hemodynamics and oxygen transport as the independent variables in the $\mathbf{1 6}$ neonates during the first $\mathbf{7 2}$ hours after the Norwood procedure using mixed linear regression method

\begin{tabular}{|c|c|c|c|}
\hline Independent variables & Intercept & $\begin{array}{l}\text { Parameter } \\
\text { estimate }\end{array}$ & $P$ values \\
\hline SAP (mm Hg) & 34.9 & 0.31 & $<.0001$ \\
\hline $\mathrm{DAP}(\mathrm{mm} \mathrm{Hg})$ & 46.3 & 0.26 & .0003 \\
\hline $\mathrm{MAP}(\mathrm{mm} \mathrm{Hg})$ & 33.8 & 0.48 & $<.0001$ \\
\hline SVR (Wood unit $\cdot \mathrm{m}^{2}$ ) & 57.0 & -0.15 & .003 \\
\hline $\mathrm{Hb}(\mathrm{g} / \mathrm{dL})$ & 46.2 & 0.64 & .02 \\
\hline $\mathrm{SaO}_{2}(\%)$ & 24.8 & 0.41 & $<.0001$ \\
\hline $\mathrm{PaO}_{2}(\mathrm{~mm} \mathrm{Hg})$ & 26.9 & 0.69 & $<.0001$ \\
\hline$O p\left(L \cdot \min ^{-1} \cdot \mathrm{m}^{-2}\right)$ & 51.0 & 1.8 & .001 \\
\hline Os $\left(\mathrm{L} \cdot \mathrm{min}^{-1} \cdot \mathrm{m}^{-2}\right)$ & 50.1 & 2.1 & $<.0001$ \\
\hline $\mathrm{DO}_{2}\left(\mathrm{~mL} \cdot \min ^{-1} \cdot \mathrm{m}^{-2}\right)$ & 47.8 & 0.023 & $<.0001$ \\
\hline $\mathrm{V}_{2}\left(\mathrm{~mL} \cdot \min ^{-1} \cdot \mathrm{m}^{-2}\right)$ & 58.1 & -0.03 & .13 \\
\hline $\mathrm{ERO}_{2}$ & 64.4 & -31.0 & $<.0001$ \\
\hline
\end{tabular}

For abbreviations see Table 2. 